formance of this work, the comments would have possibly been forgotten by the individual who was expected to write them out. However, a modification of this system has been ound to work very well in some Societies where the Secretary supplies every participant in a discussion with a printed abstract of his remarks, with a request to make corrections and supply deficiencies. Very truly yours,

B. A. Watson, M.D.

Jersey City, Oct. 23, 1886.

\section{SHORTENING OF BONE IN DESTRUCTION OF SOFT PARTS.}

To THE EDITOR OF THE JOURNAL: 、

Dear Sir:-Seeing that in these days priority is considered of so much importance, may I be allowed to point out, that though Dr. Martel, of St. Malo, as mentioned in your issue of August 14, (p. 176), may have been the first to conceive the idea of removing a portion of bone in order to facilitate cicatrisation in cases where there is extensive destruction of soft parts, he was not the first to perform or put on record such an operation. It was done in the Royal Infirmary of Edinburgh, in May, I885, by Mr. Joseph Bell, in the case of a patient, who, during a severe attack of phlegmonous erysipelas, lost the greater part of the skin of the inside of the right arm from the posterior fold of the axilla, down to within three inches of the wrist-joint. He was sent into the Infirmary for amputation, his doctor considering it impossible that such a sore could be healed. Mr. Bell being loth to sacrifice the arm, tried skin-grafting, with the result that cicatrisation progressed till only a wound about 3 inches long by 1 broad, remained on the inside of the elbow.joint. As this refused to heal further, Mr. Bell made up his mind to shorten the arm by removing a portion of the humerus. On May 27, 1885 , about eight months before Dr. Martel's operation was performed, the lower three inches of the bone, including the condyles, cartilage and also the olecranon were removed. The result was a complete success, the patient recovering with a useful arm, soundly healed, with full flexion, extension, pro. nation and supination. The case was recorded in the Edinburgh Medical Journal for September, 1885. I am, yours faithfully,

Edinburgh, Sept. 9, 1886. J. Maxwet. Ross.

NAPHTHALINE IN RENAL, AFFECTIONS.

TO THI EDITOR OF THI: JOURNAY:

Dear Sir:-I noticed in a recent number of the British Medical Journal, under the head of Correspondence, the following: " $M$. de Pezzer treats certain renal affections with naphthaline, especially those that are accompanied with difficult micturition; and, when fetid urine is passed, the results are generally good. In pyelonephritis, $M$. de Perker gives a gramme and a half, also in cystitis and prostatitis, with retention of urine, likewise for stricture complicated by fistula." The above, unfortunately, has been quoted by several of our American journals.
To those who are not familiar with the action of naphthaline on the urinary organs I deem it my duty to say that if employed in the conditions recom. mended above by $M$. de Pezzer, even in much smaller doses - 5 grains - it quickly excites intense irritation of the urinary passages. I have more than once observed the most violent cystitis excited by 5 -grain doses of naphthaline. In one instance two 5-grain doses brought on violent vesical tenesmus, backache and fever, the vesical spasms recurring every fifteen minutes for two days, and the cystitis failed to yield to the ordinary measures for nearly two weeks.

In cunditions of perfect health the urinary organs will often tolerate the use of naphthaline in considerable doses when given by the mouth; but I should especially avoid its administration in the conditions named by $M$. de Pezzer, ample experience having proven to me that in such conditions its action is most pernicious. Chas. W. Purdy, M.D.

163 State St., Chicago, Oct. 21, 1886.

\section{MISCELLANEOUS.}

All membership dues should be sent direct to the Treasurer, Richard J. Dungi.ison, M.D., lock box 1 274 , Philadelphia, Penn.

OFFICIAL LIST OF CHANGES IN THE STATIONS AND DUTIES OF OFFICERS SERVING IN THE MEDICAL DEPARTMENT. U. S. ARMY, IROM OCTOBER 36, 8886 , TO OC'TOBER 22, 1886 .

Capt. Daniel Weisel, Asst. Surgeon, relieved from duty at $\mathrm{Ft}$. Fred Steele, Wyo., and ordered to proceed to and take sta. tion at $\mathrm{Ft}$. Mckinney, Wyo., reporting to the commanding officer of that post for duty. (S. O. 135, Dept. P'atte, Oct. 15, 1886.)

First Lieut. Guy L. Edie, Asst. Surgeon, having returned from detached service in Dept. of A rizona, will join his station at FL. Mclntosh, Texas. (S. O. 144, Dept. Texas, Oct. I3, 1886.)

First Lieut. Alonzo R. Chapin, Asst. Surgeon, relieved from duty at Ft. Laramie, Wyo., and ortered to $\mathrm{Ft}$. Washalie, Wyo. (S. O. 137, Dept. Platte, Oct. 19, I886.)

First Lieut. Francis J. Ives, Asst. Surgeon, in obedience to instructions received from the division commander, ordered to report in person at hdirs. 1)ept. of the Platte, for duty. (S. O. 146, Dept. Texas, Oct. I6, I886.)

First Lieut. Wnr. P. Kendall, leave of absence extended fifteen days. (S. O. 239, A. G. O., Oct. 14, 1886.)

First Ijeut. W. B. Banister, Asst. Surgeon, assigned to duty at $\mathrm{Ft}$. Wingate, N. M. (1F. O. 97, Dept. Arizona, Sept. 29, 1886.)

First Lieut. Chas. F. Mason, Asst. Surgeon, relieved from temporary duty at $\mathrm{Ft}$. Verde, A. T., and ordered for duty at $\mathrm{Ft}$. Huachnea, A. T. (S. O. 99, Dept. Arjz., Oct. 12, 1886.)

OFFICIAI. IIST OH CHANGES OF STATIONS AND DUTIES OF MEDICAT, OFFICERS OF THE U. S. MARINE HOS PITAI SERVICE VOR IHE TWO WEEKS ENDED OCTOBER 23, 2886 .

Urquhatt, F. M., P. $\Lambda$. Surgeon, relieved from duty at Cape Charles Quarantine, to proceed to Washington, ID. C., with Str. "Woodiworth." Oct. 20, 1886.

Wasdin, Eugene, I. A. Surgeon, promoted and appointed P. A. Surgeon, from Oct. I, 1886 . Oct. 20, 1886.

Williams, L. L., Asst. Surgeon, granted leave of absence for three days. Oct. 16,1886 . 